Article

\title{
Biphenyl/PCB Degrading $b p h$ Genes of Ten Bacterial Strains Isolated from Biphenyl-Contaminated Soil in Kitakyushu, Japan: Comparative and Dynamic Features as Integrative Conjugative Elements (ICEs)
}

\author{
Jun Hirose ${ }^{1, *}$, Hidehiko Fujihara ${ }^{2}$, Takahito Watanabe ${ }^{3}$, Nobutada Kimura ${ }^{4}$, Hikaru Suenaga ${ }^{5}$, \\ Taiki Futagami ${ }^{6}{ }^{\circ}$, Masatoshi Goto ${ }^{7}$, Akiko Suyama ${ }^{2}$ and Kensuke Furukawa ${ }^{2}$ \\ 1 Department of Applied Chemistry, Faculty of Engineering, University of Miyazaki, Miyazaki 889-2192, Japan \\ 2 Department of Food and Fermentation Sciences, Faculty of Food and Nutrition Sciences, Beppu University, \\ Beppu 874-8501, Japan; fujihara@nm.beppu-u.ac.jp (H.F.); aksuyama@nm.beppu-u.ac.jp (A.S.); \\ kfurukaw@nm.beppu-u.ac.jp (K.F.) \\ 3 Research Institute for Sustainable Humanosphere, Kyoto University, Uji 611-0011, Japan; \\ takahito@rish.kyoto-u.ac.jp \\ 4 Bioproduction Research Institute, National Institute of Advanced Industrial Science and Technology (AIST), \\ Tsukuba 305-8566, Japan; n-kimura@aist.go.jp \\ 5 Biotechnology Research Institute for Drug Discovery, National Institute of Advanced Industrial Science and \\ Technology (AIST), Tokyo 135-0064, Japan; suenaga-hikaru@aist.go.jp \\ 6 Education and Research Center for Fermentation Studies, Faculty of Agriculture, Kagoshima University, \\ Kagoshima 890-0065, Japan; futagami@chem.agri.kagoshima-u.ac.jp \\ 7 Faculty of Agriculture, Saga University, Saga 840-8502, Japan; mgoto@cc.saga-u.ac.jp \\ * Correspondence: jhirose@cc.miyazaki-u.ac.jp; Tel.: +81-985-58-7322
}

Received: 30 March 2019; Accepted: 20 May 2019; Published: 27 May 2019

\begin{abstract}
We sequenced the entire genomes of ten biphenyl/PCB degrading bacterial strains (KF strains) isolated from biphenyl-contaminated soil in Kitakyushu, Japan. All the strains were Gram-negative bacteria belonging to $\beta$ - and $\gamma$-proteobacteria. Out of the ten strains, nine strains carried a biphenyl catabolic bph gene cluster as integrative conjugative elements (ICEs), and they were classified into four groups based on the structural features of the bph genes. Group I (five strains) possessed bph genes that were very similar to the ones in Pseudomonas furukawaii KF707 (formerly Pseudomonas pseudoalcaligenes KF707), which is one of the best characterized biphenyl-utilizing strains. This group of strains carried salicylate catabolic sal genes that were approximately 6-kb downstream of the bph genes. Group II (two strains) possessed bph and sal genes similar to the ones in KF707, but these strains lacked the $b p h X$ region between $b p h C$ and $b p h D$, which is involved in the downstream catabolism of biphenyl. These bph-sal clusters in groups I and II were located on an integrative conjugative element that was larger than $110 \mathrm{~kb}$, and they were named ICE $\mathrm{Ibph}_{\text {-sal }}$. Our previous study demonstrated that the ICE $\mathrm{Iph}_{\text {bsal }}$ of Pseudomonas putida KF715 in group II existed both in an integrated form in the chromosome (referred to as $\mathrm{ICE}_{\text {bph-sal }} \mathrm{KF} 715$ (integrated)) and in a extrachromosomal circular form (referred to as $\mathrm{ICE}_{\text {bph-sal }}$ (circular)) (previously called pKF715A, $483 \mathrm{~kb}$ ) in the stationary culture. The ICE $\mathrm{I}_{\text {bph-sal }}$ was transferred from KF715 into P. putida AC30 and P. putida KT2440 with high frequency, and it was maintained stably as an extrachromosomal circular form. The $\mathrm{ICE}_{\text {bph-sal }} \mathrm{KF715}$ (circular) in these transconjugants was further transferred to P. putida F39/D and then integrated into the chromosome in one or two copies. Meanwhile, group III (one strain) possessed bph genes, but not sal genes. The nucleotide sequences of the $b p h$ genes in this group were less conserved compared to the genes of the strains belonging to groups I and II. Currently, there is no evidence to indicate that the bph genes in group III are carried by a mobile element. Group IV (two strains) carried bph genes as ICEs (59-61 kb) that were similar to the genes found in Tn 4371 from Cupriavidus oxalacticus A5 and
\end{abstract}


$\mathrm{ICE}_{\mathrm{KKS102}} 4677$ from the Acidovorax sp. strain KKS102. Our study found that $b p h$ gene islands have integrative functions, are transferred among soil bacteria, and are diversified through modification.

Keywords: biphenyl; bph gene; integrative conjugative element; genome sequence

\section{Introduction}

To date, a number of biphenyl-utilizing bacteria have been isolated and characterized in terms of the degradation of polychlorinated biphenyls (PCBs), which are serious environmental contaminants that are prevalent worldwide [1-3]. These strains include both Gram-negative and Gram-positive bacteria. Biphenyl catabolic enzymes co-metabolize certain PCBs into chlorobenzoic acids. It is well documented that PCB degradation is highly dependent on chlorine substitutions, such as the number and positions of the substituted chlorine [4]. Degradation capabilities are also strain dependent. For the first time, biphenyl catabolic bph genes were cloned from Pseudomonas furukawaii KF707 [5]. Since then, $b p h$ genes were cloned from various strains, including both Gram-negative and Gram-positive bacteria, and then they were analyzed in detail [3]. These studies indicated that some strains possessed $b p h$ genes that were very similar to the ones in KF707 in terms of gene organization and nucleotide sequences, although some strains possessed bph gene clusters that were different from KF707 and diversified from each other [3]. Some $b p h$ genes are located on chromosomes, whereas others are present on plasmids. The bph genes of C. oxalacticus A5 (formerly Ralstonia sp. strain A5) [6] and Acidovorax sp. KKS102 [7] are located on the ICEs. Gram-positive Rhodococcus jostii RHA1 possesses multiple bph genes on large linear plasmids $[8,9]$.

The typical bph gene cluster shown in KF707 is composed of bphRA1A2A3A4BCX0X1X2X3D (Figure 1) [3]. Briefly, the biphenyl dioxygenase is a multi-component enzyme encoded by bphA1A2A3A4, and it catalyzes the initial oxygenation of biphenyl, converting the biphenyl into dihydrodiol, where $b p h A 1$ and $b p h A 2$ encode a large and a small subunit of the terminal dioxygenase, respectively. $b p h A 3$ encodes ferredoxin, and $b p h A 4$ encodes ferredoxin reductase. The dihydrodiol compound is then converted to a dihydroxy-compound by the dehydrogenase encoded by the $b p h B$. The dihydroxy-compound is then degraded into 2-hydroxy-6-oxo-6-phenylhexa-2,4-dienoic acid by the ring-cleavage dioxygenase encoded by the $b p h C$. Then, the ring meta-cleavage compound is degraded into benzoic acid and 2-hydroxypenta-2,4-dienoic acid by the hydrolase (encoded by the $b p h D)$. BphX1X2X3 is responsible for the further degradation of 2-hydroxypenta-2,4-dienoic acid into acetyl CoA. These structural $b p h$ genes are regulated by the $b p h R$ located on the $b p h$ gene cluster $[10,11]$ Among these $b p h$ genes, $b p h A 1$ is critically important for substrate specificity, i.e., the biodegradation capability for various aromatic compounds, including PCBs [12-14].

Previously, we isolated more than ten biphenyl-utilizing bacterial strains (KF strains) from biphenyl-contaminated soil in Kitakyushu, Japan [15]. Among these KF strains, we determined the complete nucleotide sequence of the P. putida KF715 genome [16], which revealed five replicons: one circular chromosome and four plasmids. Southern blot analysis indicated that the majority of the KF715 cell population carried the bph-sal cluster on its chromosome. However, a small population of cells carried the cluster on a huge extrachromosomal circular element called pKF715A (483 kb). In addition, this element carried the oriT sequence, the rep $A$ gene involved in replication, the conjugal transfer gene (tra), and the partitioning gene (par). In this study, we were interested in how the KF strains isolated from the same location carried bph gene clusters along with other catabolic genes. We performed whole genome sequencing of these strains, anticipating that their genome information would shed light on the diversity and evolution of biphenyl-utilizing bacteria. Our results indicated that specific DNA blocks, including the bph gene cluster, were integrated within glycine tRNA (tRNA-Gly) genes and that some blocks contained an integrase gene, illustrating that certain bph gene islands had integrative functions. 


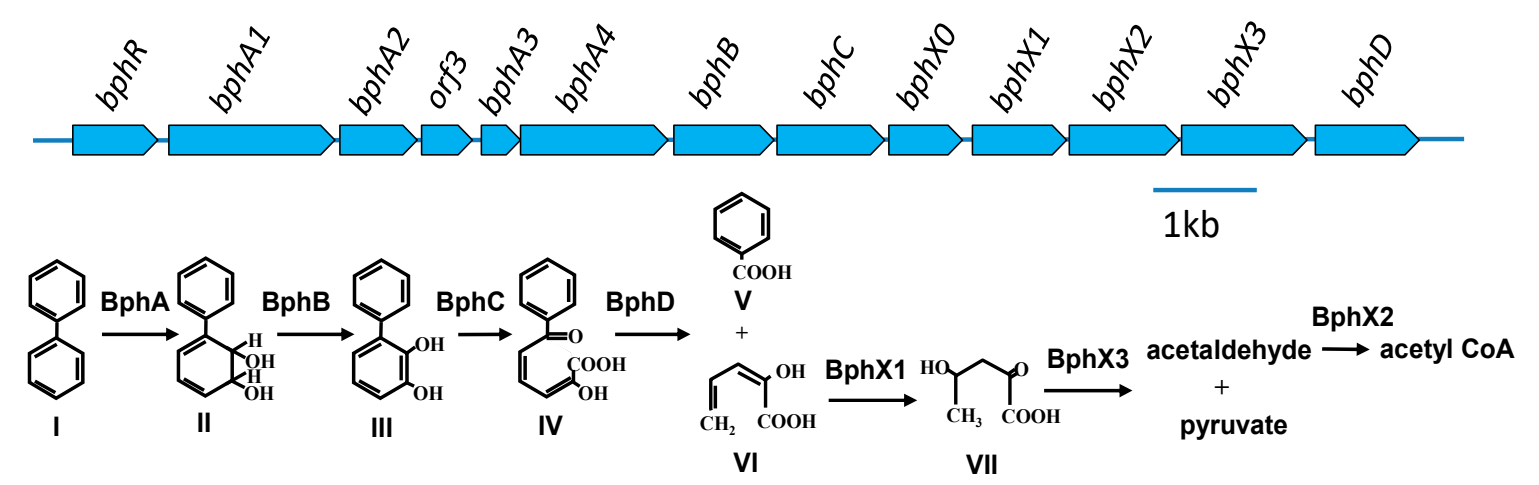

Figure 1. Catabolic pathway of the biphenyl degradation and organization of the bph gene cluster in P. furukawaii KF707. Compounds: I, biphenyl; II, 2,3-dihydroxy-4-phenylhexa-4,6-diene (dihydrodiol compound); III, 2,3-dihydroxybiphenyl; IV, 2-hydroxy-6-oxo-6-phenylhexa-2,4-dienoic acid (biphenyl meta-cleavage compound: HOPD); V, benzoic acid; VI, 2-hydroxypenta-2,4-dienoic acid; VII, 4-hydroxy-2-oxovalerate. Enzymes: BphA1-BphA2-BphA3-BphA4, biphenyl dioxygenase; $\mathrm{BphB}$, dihydrodiol dehydrogenase; BphC, 2,3-dihydroxybiphenyl dioxygenase; BphX0, glutathione S-transferase; BphX1, 2-hydroxypenta-2,4-dienoate hydratase; BphX2, acetaldehyde dehydrogenase (acylating); BphX3, 4-hydoxy-2-oxovalerate aldolase; BphD, 2-hydroxy-6-oxo-6-phenylhexa-2,4-dieonic acid hydrolase. The BphR protein, belonging to the GntR family, is a transcriptional regulator involved in the expression of $b p h R$ and $b p h X 0 X 1 X 2 X 3 D$. The function of orf3 remains unclear.

\section{Materials and Methods}

\subsection{Bacterial Strains and Cultivation}

The bacterial strains (KF strains) used in this study are presented in Table 1. These biphenyl/PCB degrading strains were isolated at the biphenyl-manufacturing factory in Kitakyushu, Japan [15], and were deposited to the National Biological Resource Center (NBRC). Strains KF701, KF703, KF707, KF708, and KF712 were renamed based on the 16S rRNA sequence [17-21]. P. putida AC30Bph+ and P. putida KT2440Bph+ were obtained through conjugation with P. putida KF715, and these two transconjugants grew on biphenyl as a sole source of carbon and energy, as described in Reference [22]. P. putida F39/D is a mutant of toluene utilizing P. putida F1 [23], in which the todD gene is defective. This strain was used as a recipient for the conjugation experiments. The growth of the KF strains and the transconjugants was examined on a basal salt agar medium with biphenyl and various aromatic compounds as described in Reference [5].

Table 1. Biphenyl/PCB degrading KF strains used in this study.

\begin{tabular}{lclc}
\hline \multicolumn{1}{c}{ Strain } & NBRC Number & DDBJ/EMBL/GenBank Accession Number & References \\
\hline Pseudomonas abietaniphila KF701 & 110664 & B BQJ01000001-BBQJ01000140 & {$[15,17]$} \\
Pseudomonas aeruginosa KF702 & 110665 & B BQK01000001-BBQK01000091 & {$[15,24]$} \\
Pseudomonas putida KF703 & 110666 & BBQL01000001-BBQL01000135 & {$[15,18]$} \\
Pseudomonas furukawaii KF707 & 110670 & AP014862 & {$[15,19,25]$} \\
Cupriavidus basilensis KF708 & 110671 & B BQM01000001-BBQM01000062 & {$[15,20]$} \\
Cupriavidus pauculus KF709 & 110672 & BBQN01000001-BBQN01000227 & {$[15,26]$} \\
Pseudomonas toyotomiensis KF710 & 110674 & BBQO01000001-BBQO01000029 & {$[15,27]$} \\
Comamonas testosteroni KF712 & 110673 & BBQP01000001-BBQP01000097 & {$[15,21]$} \\
Pseudomonas putida KF715 & 110667 & AP015029, AP015030-AP015033 & {$[15,16,22,28]$} \\
Pseudomonas stutzeri KF716 & 110668 & BBQQ01000001-BBQQ01000030 & {$[29]$} \\
\hline
\end{tabular}

\subsection{Genome Sequencing and Computational Analysis}

The whole genome sequences of the KF strains were determined by the National Institute of Technology and Evaluation (NITE), using a combination of shotgun sequencing on a 454 GS FLX+ system (Roche, Basel, Switzerland) and paired-end sequencing on a HiSeq sequencing system (Illumina, 
San Diego, CA, USA) as previously reported in Reference [17]. The reads obtained by the two systems were assembled using the Newbler version 2.8 (Roche). The draft sequence data of the P. furukawaii KF707 and P. putida KF715 were further completed using the GenoFinisher computer program (http://www.ige.tohoku.ac.jp/joho/gf_e/). Remaining gaps between the contigs were closed using polymerase chain reaction (PCR) amplification and DNA sequencing with standard Sanger technology. The genome sequences were annotated using the RAST (Rapid Annotation using Subsystem Technology) server [30]. The identification of the coding genes was checked using a BLAST search (http://www.ncb.gov/BLAST/). Sequence comparison was performed using EasyFig Ver. 2.1 [31], and the map was generated using drawGeneArrows3 (http://www.ige.tohoku.ac.jp/joho/labhome/tool.html). The whole genome sequences of the 10 strains were deposited to the DDBJ/EMBL/GenBank under the accession numbers presented in Table 1 . The nucleotide sequences of the integrative conjugative elements in KF701, KF702, KF703, KF707, KF708, KF710, KF712, and KF716 were deposited separately. Their accession numbers were LC469607, LC469608, LC469609, LC469610, LC469611, LC469612, LC469613, and LC469614, respectively.

\subsection{Phylogenetic Analysis and Gene Alignment}

The nucleotide sequences were aligned computationally using the ClustalW algorithm as in Reference [32]. Phylogenetic trees were generated using the neighbor-joining method with the Mega 6.0 program [33]. The trees were evaluated through bootstrap resampling (500 replicates).

\subsection{Conjugation Experiments}

Transfer of the $\mathrm{Bph}^{+}$phenotype (P. putida AC30Bph+ and P. putida KT2440Bph+) by conjugation into the recipient cells (P. putida F39/D) was carried out through filter mating as described in Reference [22].

\subsection{DNA Manipulation}

DNA isolation, Southern blot analysis, PCR, DNA sequencing, and other DNA manipulations were performed according to standard procedures as described in Reference [34]. Pulsed-field gel electrophoresis was performed in accordance with the manufacturer's instructions (Bio-Rad Laboratories, Hercules, CA, USA).

\section{Results}

\subsection{KF Strains and their Genomic Features}

In this study, we found that various types of $b p h$ genes were present in the ten biphenyl/PCB degrading strains isolated from the biphenyl-contaminated soil. Figure 2 shows the 16S rRNA phylogenetic tree of the ten strains. Among the ten strains, seven belonged to the Pseudomonas genus, two strains to Cupriavidus spp., and one to Comamonas spp. These were all Gram-negative bacteria belonging to $\beta$-proteobacteria (Comamonas and Cupriavidus) and $\gamma$-proteobacteria (Pseudomonas). The complete genome sequences were determined for P. furukawaii KF707 and P. putida KF715. KF707 possessed one circular chromosome of 6,242,949 bp and one plasmid (pKF707) of 59,819 bp. On the other hand, P. putida KF715 possessed one circular chromosome of 6,583,376 bp and four plasmids as previously reported in Reference [16]. The total length of the contigs (total number of contigs, $>500 \mathrm{bp}$ ) of the remaining strains were as follows: P. abietaniphila KF701, 6,886,250 bp (140) [17]; P. aeruginosa KF702, 7,167,540 bp (91) [24]; P. putida KF703, 6,434,897 bp (135) [18]; C. basilensis KF708, 7,826,077 bp (62) [20]; C. pauculus KF709, 6,826,799 bp (227) [24]; P. toyotomiensis KF710, 5,596,721 bp (29) [27]; C. testosteroni KF712, 5,890,323 bp (97) [21]; and P. stutzeri KF716, 4,188,013 bp (30) [29]. 


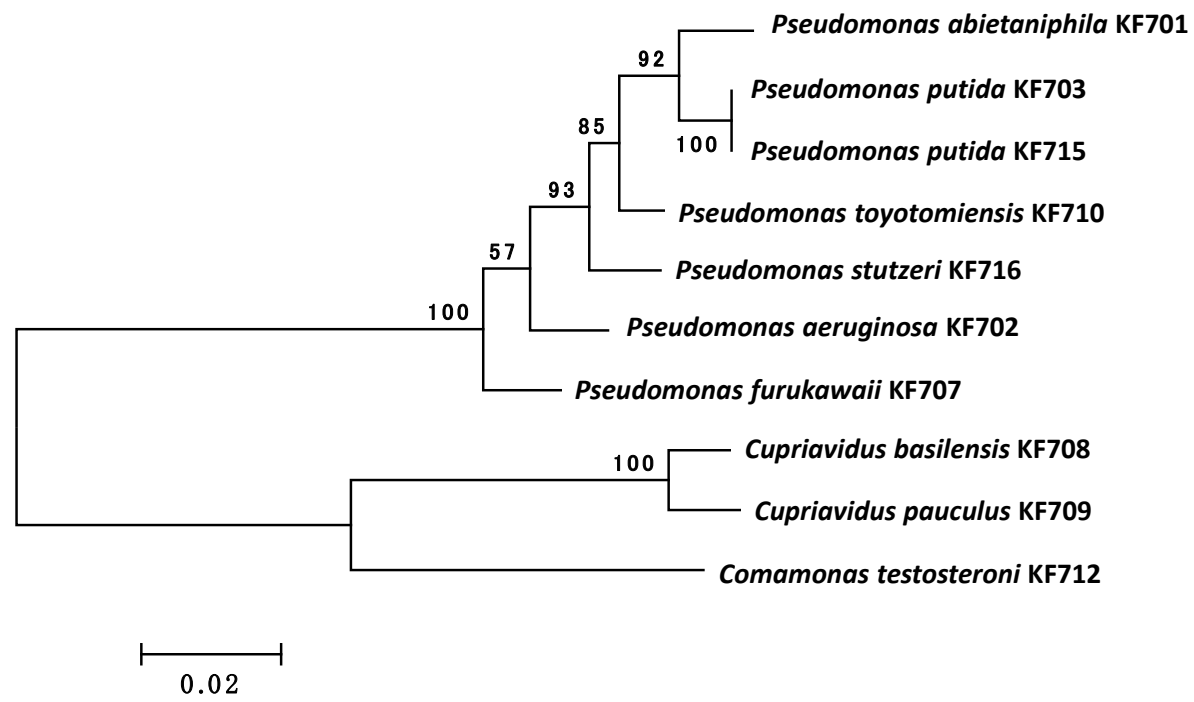

Figure 2. 16S rRNA phylogenetic trees of the ten KF strains. The multiple alignment outputs were used to generate neighbor-joining phylogenetic trees using MEGA 6.0 [33]. The bar indicates expected nucleotide substitutions per site. Numbers indicate the percentage occurrence of the branch in the bootstrapped trees on 500 replicates.

All ten strains possessed the bph genes, while seven strains possessed the salicylate catabolic sal genes. The bph-sal cluster was localized on the chromosome in KF707. The same cluster was located on the chromosome in the majority of the KF715 cells and also existed as an extrachromosomal circular form $(483,376 \mathrm{bp})$ as well in the minor part of the cells in the stationary phase culture [16]. Based on the features of the bph genes, we classified the ten strains into four groups. Group I (five strains) possessed the bph-sal cluster that was almost identical to that of KF707, where the sal genes were localized approximately 6-kb downstream of the $b p h$ genes. This group included strains KF702, KF703, KF707, KF710, and KF716. The $b p h$ gene cluster of this group was composed of $b p h R A 1 A 2 A 3 A 4 B C X 0 X 1 X 2 X 3 D$ $(11.2 \mathrm{~kb})$, which encodes the catabolic enzymes that degrade biphenyl into benzoate and acetyl CoA via the meta-cleavage pathway. Group II (strains KF701 and KF715) possessed the bph-sal cluster that was similar to that of KF707, although the bphX region $(3.5 \mathrm{~kb})$ that is involved in the metabolism of 2-hydroxypenta-2,6-dienoic acid to acetyl CoA (Figure 1, lower pathway of biphenyl metabolism) was deleted as described in Reference [22]. The structural features of the $b p h R A B C D(7.8 \mathrm{~kb})$ and the flanking regions, including the sal genes $(10.2 \mathrm{~kb})$, were almost identical between KF701 and KF715, indicating that the $b p h$-sal clusters of these two strains were horizontally transferred to one another. Group III (KF709) possessed the bph genes, but not the adjacent sal genes as in the case of Burkholderia xenovorans LB400 [35], another well-characterized PCB-degrader. Overall alignment of the bph gene cluster in KF709 was similar to that of group I, but each bph component of the bph genes was relatively low. Group IV (KF708 and KF712) possessed bph genes similar to the genes found in Tn4371 from C. oxalacticus A5 [6], and the ones in $\mathrm{ICE}_{\mathrm{KKS} 102} 4677$ from the Acidovorax sp. strain KKS102 [7]. Some rearrangements of the $b p h$ gene cluster were observed compared to that in groups I-III as described below. This group of strains did not carry the sal genes.

All the strains possessed the catabolic genes of benzoate, the lower pathway intermediate of biphenyl catabolism. Strains KF701, KF702, KF703, KF707, KF710, and KF715 possessed multiple benzoate catabolic genes that encoded both the extradiol cleavage meta-pathways ( $b z a)$ and intradiol cleavage ortho-pathways (ben). KF708, KF709, and KF712 possessed the box genes encoding the benzoate catabolic pathway via benzoyl-CoA. Besides the $b p h$, sal, and benzoate catabolic (bza, ben, and box) genes, these ten strains possessed catabolic genes for various aromatic compounds. Eight strains (KF701, KF703, KF707, KF708, KF710, KF712, KF715, and KF716) possessed a phenol-catabolic dmp gene cluster [36]. Five strains (KF702, KF703, KF707, KF710 and KF715) had protocatechuate catabolic 
pca genes. Five strains (KF703, KF707, KF708, KF709 and KF715) possessed phenylacetate catabolic paa genes. Other than the aromatic catabolic genes, many strains carried heavy metal-resistant genes. Six strains (KF701, KF702, KF708, KF710, KF712, and KF715) possessed a cluster of mer genes that were responsible for the resistance of inorganic mercury [37]. All of the ten strains possessed putative $c z c$ genes involved in the resistance of cobalt, zinc, and cadmium [38]. In KF708 and KF709, more than ten putative $c z c$ gene clusters were present. Arsenate-resistant genes were present in all the ten strains. These results, except for the arsenate-resistant genes, are summarized in Table S1.

\subsection{Comparison of the bph Genes}

The identities (percent) of the nucleotide sequences of the bph genes in groups I-IV strains (named as types I-IV bph genes, respectively) are shown in Tables S2-S13. The phylogenetic trees of $b p h A 1$, $b p h B, b p h C$, and $b p h D$ belonging to types I and II are shown in Figure 3. A comparative analysis of the nucleotide sequences of each gene revealed that all the $b p h$ genes were almost identical in types I and II (96.7-100\%), except for that of the $b p h X$ region $(3.5 \mathrm{~kb})$ between $b p h C$ and $b p h D$, which was missing in the bph gene cluster of type II (Figure 4).
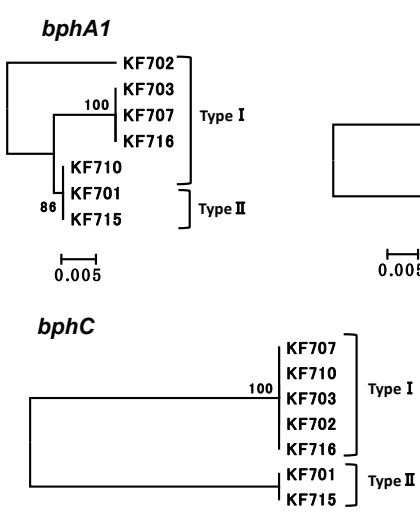

$\stackrel{\overrightarrow{0}}{\stackrel{005}{10}}$

$\stackrel{\longmapsto}{\longrightarrow 005}$
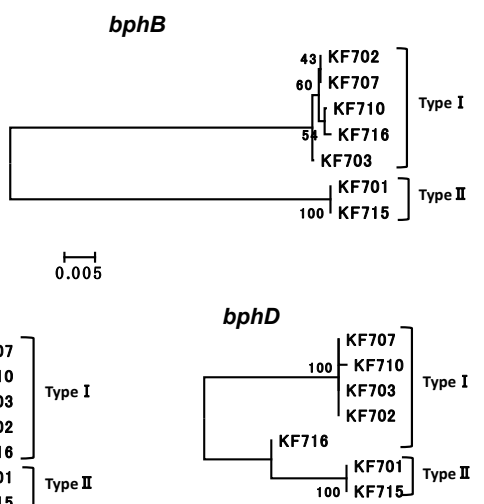

$\stackrel{\longmapsto}{0.005}$

Figure 3. Phylogenetic tree of $b p h A 1, b p h B, b p h C$, and $b p h D$ of KF strains in groups I and II (types I and II $b p h$ genes). The multiple alignment outputs were used to generate neighbor-joining phylogenetic trees using MEGA 6.0 [33]. The bar indicates expected nucleotide substitutions per site.

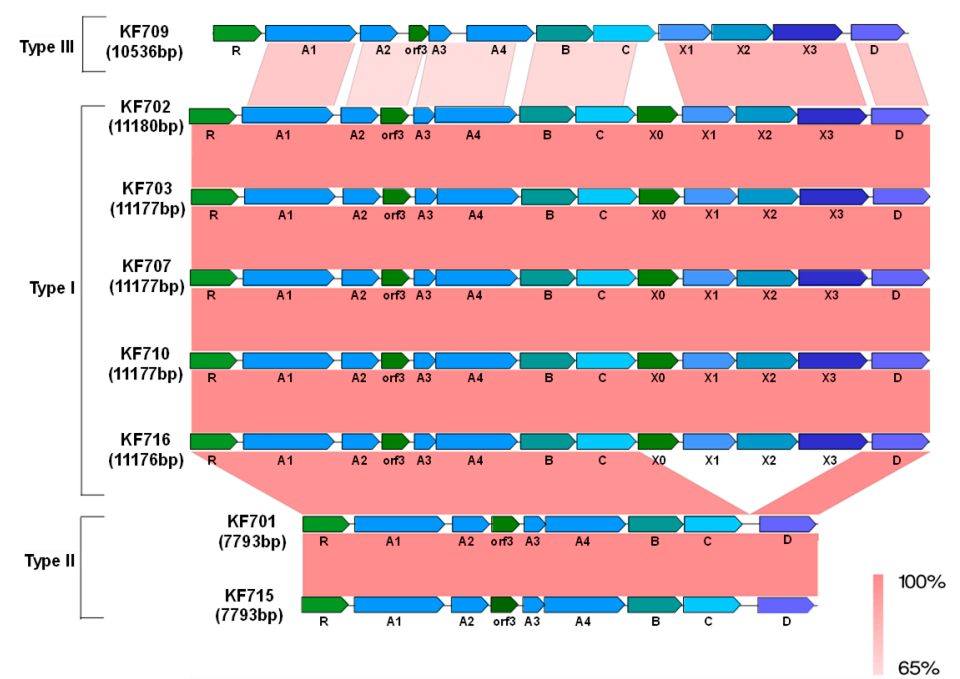

Figure 4. Comparison of the $b p h$ gene clusters of KF strains belonging to groups I-III (types I-III). The shading in pink to red shows the identity (65-100\%) of the gene clusters as indicated at the bottom of the figure. R, bphR; $\mathrm{A} 1, b p h A 1 ; \mathrm{A} 2, b p h A 2 ; \mathrm{A} 3, b p h A 3 ; \mathrm{A} 4, b p h A 4 ; \mathrm{B}, b p h B ; \mathrm{C}, b p h C ; \mathrm{D}, b p h D ; \mathrm{X} 0, b p h X 0$, $\mathrm{X} 1, b p h X 1 ; \mathrm{X} 2, b p h X 2 ;$ and $\mathrm{X} 3, b p h \mathrm{X} 3$. 
The $b p h A 1, b p h A 2, b p h A 3, b p h A 4, b p h B$, and $b p h C$ genes of KF716 were almost identical to that of the type I bph gene. However, the 3'-terminus of the bphX3 gene (754 bp) and $5^{\prime}$-terminus of the $b p h D$ gene (260 bp) of KF716 were different from that of type I (Figure S1a,b), and the $5^{\prime}$-terminus of the $b p h D$ gene $(260 \mathrm{bp})$ of KF716 was almost identical to that of the type II bph gene. These genetic features are reflected in the phylogenetic tree of the $b p h D$ (Figure 3). Thus, the bph genes of KF716 showed the structural features of both groups I and II.

The KF709 (group III strain) possessed a type III bph gene similar to the one in group I, but the respective $b p h$ genes were less conserved and rearranged (Figure 4). The nucleotide sequences of the KF709 bph genes had less than $72.7 \%$ identities compared to types I and II in the bphABC region $(5.9 \mathrm{~kb})$. However, the $b p h X 1, X 2, X 3$ genes and $b p h D$ gene were more identical (88.6-90.6\% in $b p h X 1$ and $74.3-84.9 \%$ in $b p h X 2, b p h X 2, b p h X 3$, or $b p h D$ ) (Tables S2-S13). The $b p h X 0$ encoding putative glutathione $S$-transferase was not present between the $b p h C$ and $b p h X 1$, but it was located downstream of the tRNA-Gly gene (data not shown). orf 3 was present between the $b p h A 2$ and $b p h A 3$ of types I-III. Despite the conserved feature of orf3, its function remains unclear [3].

The genetic features of KF708 and KF712 in the group IV strain bph genes (Type IV bph gene) were very different to types I and II, yet they were similar to those of the Acidovorax sp. strain KKS102 and C. oxalacticus A5 (Figure 5). The bph gene cluster of this type was composed of $b p h S X 1 X 2 X 3(V) A 1 A 2 A 3 B C D(W) A 4$. Thus, the $b p h X 1 X 2 X 3$ region was located upstream of the $b p h A 1 A 2 A 3 B C D$ region, and $b p h A 4$ was present just downstream of the $b p h D$ (Figure 5). The insertion sequence (1190 bp) and the transposase gene (IS/tnp) were present between the bphS and bphX1 of KF708 and KKS102 [39], but these were not present in KF712 and C. oxalacticus A5. The identity of the KF708 and KF712 bph genes of type IV was compared to types I and II (Tables S2-S13). The nucleotide sequences of $b p h A 1, b p h A 2, b p h A 3, b p h A 4, b p h B, b p h C$, and $b p h D$ were conserved between types I and IV; however, the identities were less than $77 \%$. Two unidentified gene components, $b p h V$ and $b p h W$, were present in all the type IV bph genes, but they were not present in types I-III. The type IV bph genes possessed a transcriptional regulator, $b p h S$ [39]. It was reported that $b p h S$ acts as a repressor, whereas the $b p h R$ of Type I acts as an activator for biphenyl catabolism. The functions of $b p h S$ and $b p h R$ oppose each other, although they belong to the same GntR family [10,39].

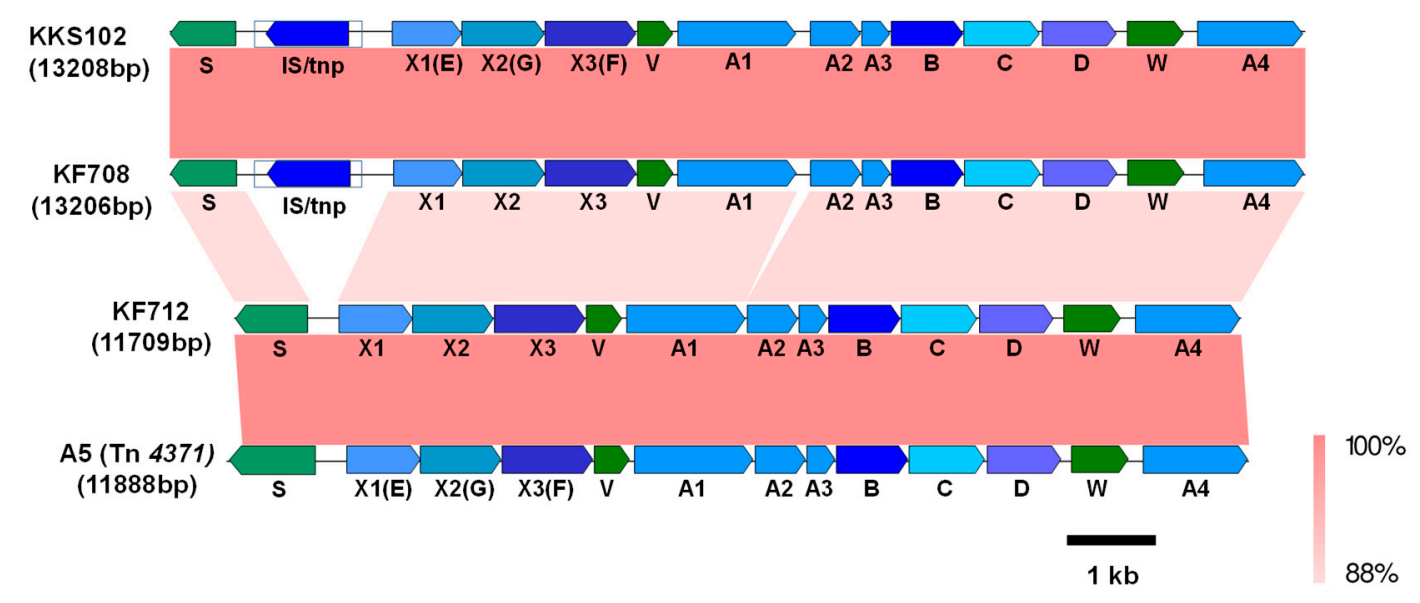

Figure 5. Comparison of the bph genes of Cupriavidus basilensis KF708 and Comamonas testosteroni KF712 belonging to group IV (type IV) to those of Acidovorax sp. KKS102 and Cupriavidus oxalacticus A5. The identities (88-100\%) between the gene clusters are shown by shading in pink to red as indicated at the right bottom of the figure. E, bphE; F, bphF; G, bphG; S, bphS; V, bphV; W, bphW; IS, insertion sequence; tnp, transposase. The $b p h E, b p h F$, and $b p h G$ of KKS102/Tn4371 are homologous genes of bphX1,bphX3, and $b p h X 2$ of KF708/KF712, respectively. The other signs are defined in the legend in Figure 4. 


\subsection{ICE $E_{b p h-s a l}$ in KF Strains Belonging to Groups I and II}

The genome sequence analysis of KF701, KF702, KF703, KF707, KF715, and KF716 revealed highly conserved large "genomic islands" that included the bph-sal genes adjacent to the tRNA-Gly(CCC) gene (Figure 6). There was an 18 bp direct repeat $\left(5^{\prime}-\mathrm{TTCCC}(\mathrm{T} / \mathrm{A})(\mathrm{T} / \mathrm{C})(\mathrm{C} / \mathrm{T})(\mathrm{G} / \mathrm{A}) \mathrm{CCCGCTCCA}-3^{\prime}\right)$ on the border of the conserved region and the non-conserved region (att $L$ and attR, Figure 7). The att $L$ included $18 \mathrm{bp}$ of the $3^{\prime}$ end of the tRNA-Gly(CCC) gene. These $18 \mathrm{bp}$ direct repeat sequences could be generated by the integration of genomic islands into the chromosome. In strain KF707, attL was followed by a phage-related integrase (int) gene. The $b p h$ cluster was located just downstream of the int gene, followed by the sal gene cluster approximately $6-\mathrm{kb}$ downstream, and by the $b z a$ gene approximately $49-\mathrm{kb}$ downstream. The $a t t R$ site was located downstream of the $b z a$ gene. Thus, the genomic island was estimated to be $122.0 \mathrm{~kb}$ in size (Figure 6). Genes identified as the VirB4 component (ATPase) and VirD4 component (coupling protein) of the type IV secretory pathway [40] were located $40-\mathrm{kb}$ and $80-\mathrm{kb}$ downstream of the tRNA-Gly(CCC) gene, respectively. The parA and parB genes encoding the replication partition proteins were present near the right end, and were proposed to act as a stabilization system for the maintenance of mobile elements in the bacterial genomes [41]. These structures corresponded to the common backbone of many integrative conjugative elements (ICEs) [42], such as ICEclc from Pseudomonas knackmussii B13 [43], which carries the catabolic genes of chlorocatechols, the tyrosine integrase gene, and type IV secretory machinery. We designated it as $\mathrm{ICE}_{\text {bph-sal }} \mathrm{KF707}$. Within this element, many putative mobile protein genes were present surrounding the sal gene cluster. To note, five IS genes at the upstream region and two IS genes at the downstream region were identified. ICE $\mathrm{E}_{b p h-s a l}$ was observed in other KF strains of group I and KF701 of group II. An ICE

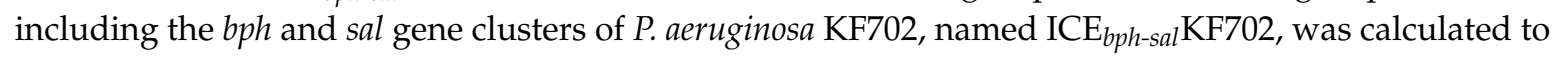
be $126.7 \mathrm{~kb}$ (Figure 6). Likewise, the $\mathrm{ICE}_{\text {bph-sal }} \mathrm{KF} 703$ of P. putida $\mathrm{KF703,} \mathrm{ICE}_{\text {bph-sal }} \mathrm{KF710}$ of P. toyotomiensis KF710, and ICE $\mathrm{E}_{\text {bph-sal }} \mathrm{KF} 716$ of P. stutzeri KF716 were calculated to be $120.8 \mathrm{~kb}, 130.3 \mathrm{~kb}$, and $117.3 \mathrm{~kb}$, respectively. The $\mathrm{ICE}_{\text {bph-sal }} \mathrm{KF701}$ of P. abietaniphila KF701 in the group II strain was $117.4 \mathrm{~kb}$ in size.

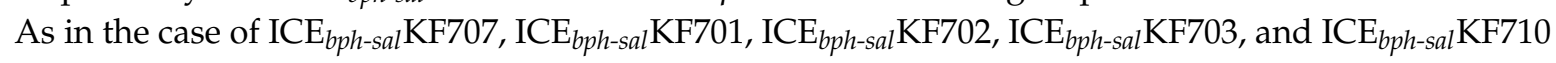
contained three gene clusters of $b p h$, sal, and $b z a$. ICE $\mathrm{I}_{b p h-s a l} \mathrm{KF} 716$ contained $b p h$ and sal genes, but not the $b z a$ genes. Sequence comparison revealed an inversion in $\mathrm{ICE}_{b p h-s a l} \mathrm{KF702}$. The sal:bza and bza:sal fusion gene clusters were found, in which half parts of the sal genes and the $b z a$ genes were replaced with each other. These fusion genes were likely generated via homologous recombination between the sal and the bza genes. ICE $\mathrm{I}_{b p h-s a l} \mathrm{KF} 710$ and $\mathrm{ICE}_{b p h-s a l} \mathrm{KF} 716$ contained the 5-kb region encoding putative multidrug efflux pumps, but $\mathrm{ICE}_{b p h-s a l} \mathrm{~s}$ from the remaining $\mathrm{KF}$ strains was deficient of the corresponding region. Thus, $\mathrm{ICE}_{b p h-s a l}$ in groups I and II contained highly conserved nucleotide sequences larger than $110 \mathrm{~kb}$, which were larger than many other ICEs found in bacterial strains to date [44].

We previously reported that KF715 harbors an approximately $90-\mathrm{kb}$ conjugative $b p h$-sal gene cluster in the chromosome [22], and that the cluster could be transferred to P. putida AC30 and P. putida KT2440 with very high frequency. Whole genome sequencing of the KF715 studied here revealed that the $b p h$-sal cluster was located on a huge $483-\mathrm{kb}$ extrachromosomal element, previously designated as pKF715A [16]. An 18 bp DNA sequence identical to the 3'- end portion of a tRNA-Gly(CCC) gene as part of its attachment site $(a t t P)$ was present just upstream of the int gene in this element. It was also confirmed that the bacterial integration site $(a t t B)$ was present within the $3^{\prime}$-end portion of a tRNA-Gly gene in the KF715 chromosome. Furthermore, the two SpeI digested bands, approximately $300 \mathrm{~kb}$ and $200 \mathrm{~kb}$, hybridized with a $b p h A 1$ probe were observed as reported [16]. Since there was only one SpeI site in the element, the large, faint band was matched to $314 \mathrm{~kb}$ of the SpeI digested extrachromosomal element. The second major band of $220 \mathrm{~kb}$ was matched to that of the SpeI digested chromosome of strain KF715. This suggested that the majority of the KF715 cells carried an integrated ICE $\mathrm{Eph}_{\text {bal }}$ KF715, whereas fewer cells carried it as an extrachromosomal circular form. Thus, it was likely that the circular form could be obtained by recombining the attL site (present at the $3^{\prime}$-end of the tRNA-Gly gene) and $a t t R$ site (present far downstream, $483 \mathrm{~kb}$ from the att $L$ site), forming the attP site. 


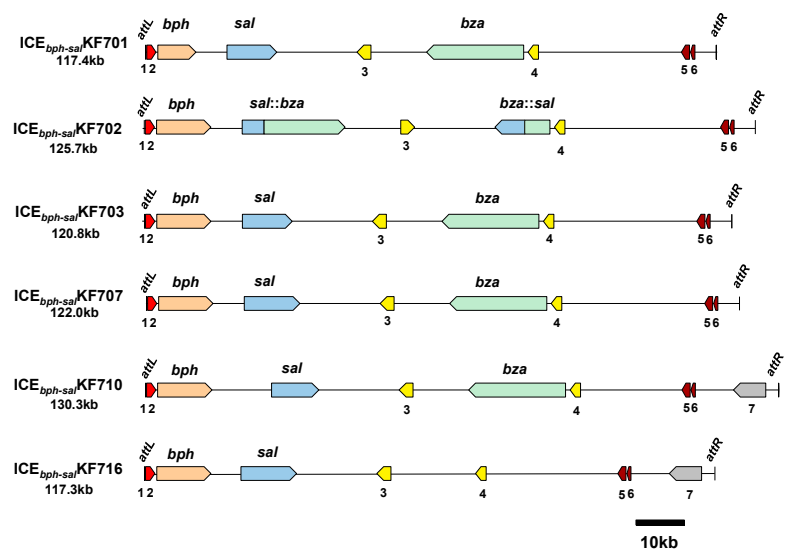

Figure 6. Organization of the ICE $\mathrm{I}_{b p h-s a l}$ in KF strains of group I and KF701 of group II. ICE $\mathrm{Iph}_{\text {bsal }} \mathrm{KF701}_{\text {, }}$

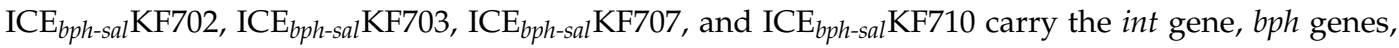
sal genes, and bza genes. ICE $\mathrm{E}_{b p h-s a l} \mathrm{KF} 716$ carries the int gene, $b p h$, and sal genes, but not the $b z a$ genes. The sal genes and $b z a$ genes in $\mathrm{ICE}_{b p h-s a l} \mathrm{KF702}$ are recombined. 1, tRNA-Gly(CCC) genes (partial); 2 , int genes; 3, VirB4 components of the type IV secretory pathway; 4, VirD4 component of the type IV secretory pathway; 5 , parB genes; 6 , parA genes; and 7, putative multidrug efflux pumps. The other, undefined gene components are not shown in the figure.

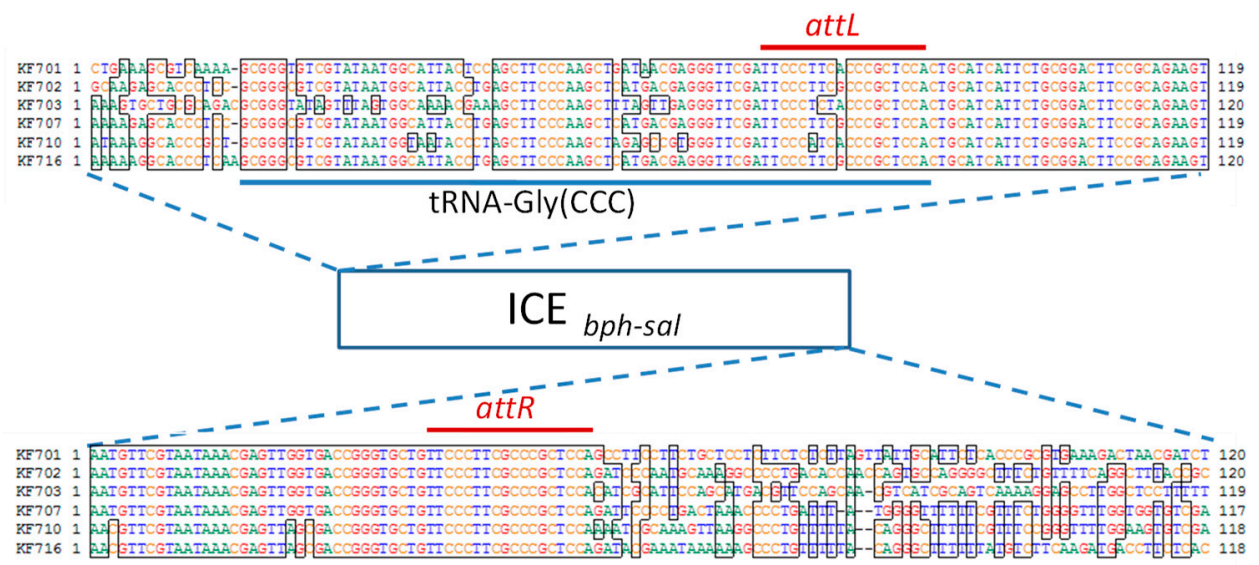

Figure 7. Integration sites of $\mathrm{ICE}_{\text {bph-sal }}$ in the KF strains of group I and KF701 of group II. The attL (18 bp) site, including $18 \mathrm{bp}$ of the 3' end of tRNA-Gly gene, and attR (18 bp) sites are indicated.

\subsection{ICEbph in the Group IV Strains}

The bph genes of C. basilensis KF708 and C. testosteroni KF712 were also located on different types of ICEs. ICE bph $\mathrm{KF} 708(61.8 \mathrm{~kb})$, including $b p h$ genes of KF708, was almost identical to ICE $\mathrm{KKS102}_{4677}$ of the Acidovorax sp. strain KKS102 [7] (Figure 8). ICE $\mathrm{Eph}_{\mathrm{K}} \mathrm{KF} 708$ had covalently bound ends of the conserved 5'-GATTTTAAG-3' sequence (attL1 and attR1). This att sequence was identical to that of ICE $\mathrm{KKS102} 4677$. Nine nucleotide substitutions, three nucleotide deletions, and one nucleotide insertion were found in $\mathrm{ICE}_{b p h} \mathrm{KF} 708$ when compared to ICE $\mathrm{KKS102} 4677$. The $\mathrm{ICE}_{b p h} \mathrm{KF} 712$ (59.4 kb) carrying the bph genes of KF712 was almost identical to the Tn 4371 from C. oxalaticus A5, being the first ICE found carrying the bph gene cluster [6]. ICE $\mathrm{E}_{b p h} \mathrm{KF} 712$ had the covalently bound ends of the conserved attL2 and attR2 sequence ( $5^{\prime}$-TTTTCAT- $\left.3^{\prime}\right)$. This att sequence was identical to that of Tn4371, but it was different from the attL1 and attR1 sequence (5'-GATTTTAAG-3') of ICE KKS102 4677 and KF708. The core part, including the $b p h$ and trb gene of $\mathrm{ICE}_{b p h} \mathrm{KF} 712$ in length of $33 \mathrm{~kb}$, was almost identical to that of $\mathrm{Tn} 4371$, whereas the remaining part flanked by the attL2 site was less conserved. Major parts of these ICEs shared common structures, including the bph gene cluster; genes encoding the replication and partition proteins; parA; VirD2 component (relaxase); as well as two conjugative transfer elements, the trb gene cluster, and the tra genes (Figure 8). $\mathrm{ICE}_{b p h} \mathrm{KF} 708$ and $\mathrm{ICE}_{\mathrm{KKS102}} 4677$ 
possessed a putative arsenate-resistant gene cluster at 15.5-18.5 kb downstream of the attL site, which encoded the transcriptional regulator, arsenate reductase, and arsenite efflux transporter. The gene cluster corresponding to them was not found in $\mathrm{ICE}_{b p h} \mathrm{KF} 712$ and Tn4371.

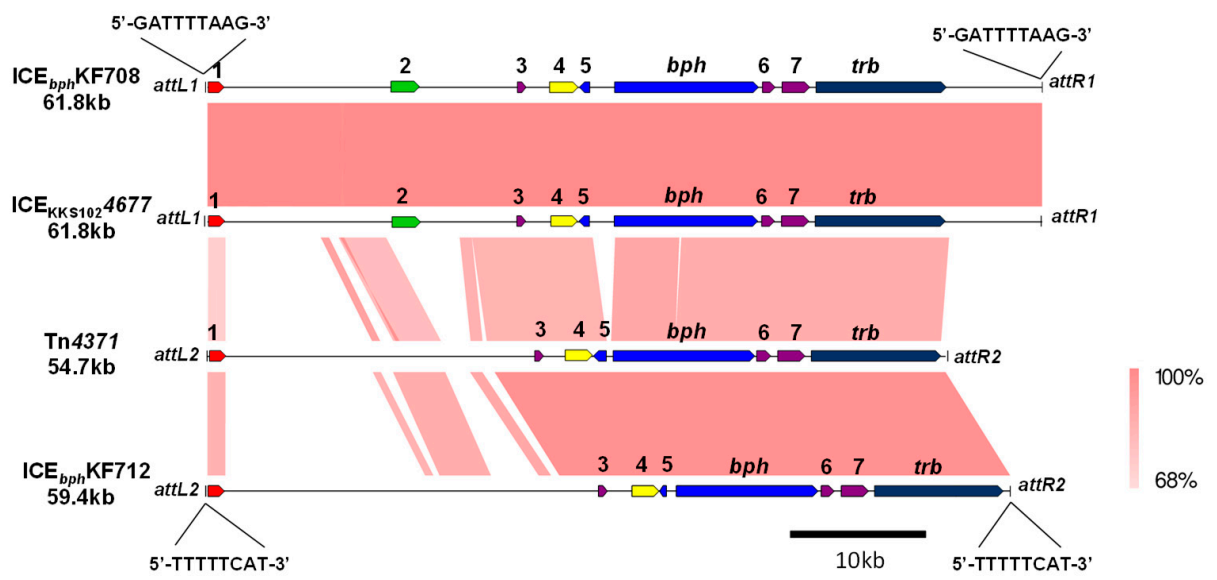

Figure 8. Organization of $\mathrm{ICE}_{b p h} \mathrm{KF} 708$ and $\mathrm{ICE}_{b p h} \mathrm{KF} 712$ in comparison to ICE $\mathrm{KKS102}_{4677}$ and Tn4371. attL1 and attR1 represent integration sites for the ICE $\mathrm{E}_{b p h} \mathrm{KF} 708$ and ICE $\mathrm{KKS102}$ 4677. attL2 and attR2 represent integration sites for the $\mathrm{Tn} 4371$ or $\mathrm{ICE}_{b p h} \mathrm{KF712}$. 1, integrase (int) gene; 2, putative arsenate-resistant gene; 3, parA gene; 4, VirD2 component (relaxase); 5, transcriptional regulator bphS gene; 6, traR gene; and 7, traG gene. The shading in pink to red shows the identities (68-100\%) of the gene clusters as indicated at the right bottom of the figure.

\subsection{Conjugal Transfer of Extrachromosomal ICEbph-salKF715 Into P. putida F39/D}

Since P. putida AC30 Bph+ and P. putida KT2440 Bph+ harbor an extrachromosomal ICEbph-salKF715, from strain KF715, we tried to transfer this element into P. putida F39/D through filter mating. The results are shown in Figure 9. Interestingly, the Bph+ transconjugant of F39/D exhibited two bands hybridized to KF715 bphA1 DNA when KT2440Bph+ was used as a donor strain of pKF715A. On the other hand, only a single band was detected when AC30Bph+ was used as a donor strain. These hybridized bands were all different in size to that of the 310-kb SpeI fragment of pKF715A, indicating that the extrachromosomal $\mathrm{ICE}_{b p h-s a l} \mathrm{KF} 715$ of the two donor strains were transferred into the recipient strain F39/D and then integrated into the chromosomes at different loci.
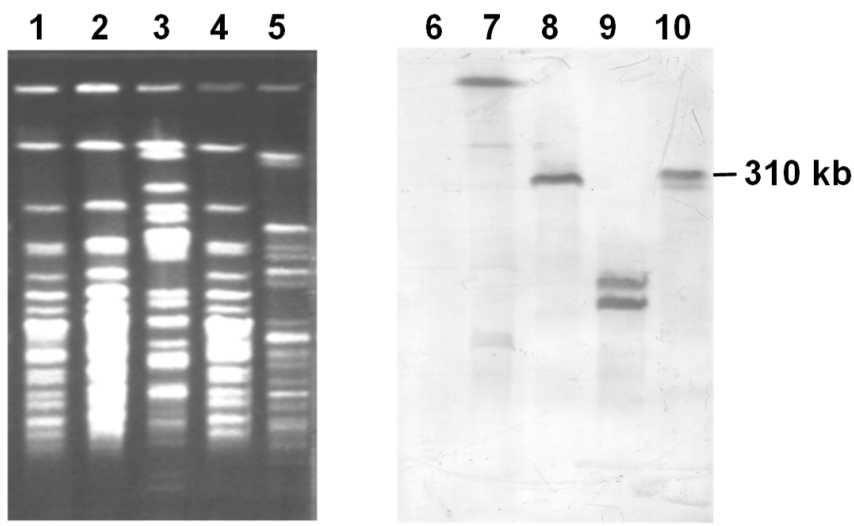

Figure 9. Conjugative transfer of the bph genes from P. putida AC30Bph+ and P. putida KT2440Bph+ into P. putida F39/D. Genomic DNA was digested with SpeI, applied to pulse field gel electrophoresis, and subjected to Southern blot analysis. The bphA1 DNA of KF715 was used as a probe. Lanes 1 and 6, F39/D; lanes 2 and 7, F39/DBph+ transconjugant from AC30Bph+; Lanes 3 and 8, AC30Bph+; Lanes 4 and 9, F39/DBph+ transconjugant from KT2440Bph+; and Lanes 5 and 10, KT2440Bph+. 


\section{Discussion}

Bacteria evolve through a variety of genetic events, such as mutations, intergenomic shuffling, and horizontal gene transfer. ICEs are being identified in increasing numbers via bacterial genomic analysis. Genomic islands, including ICEs, are discrete DNA segments and play an important role in bacterial evolution $[42,45,46]$

In this study, we revealed that $b p h$ genes differentially existed in ten biphenyl/PCB degrading strains isolated from biphenyl-contaminated soil. The types I and II bph genes of KF strains belonging to groups I and II were very similar in terms of gene organization and nucleotide sequences, except that the $b p h X$ region was missing in the type II $b p h$ gene cluster. The ICE structures carrying the $b p h$ genes were identified in several strains. Typical $\mathrm{ICE}_{b p h \text {-sal }}$ of approximately $120 \mathrm{~kb}$ was observed in the group I strains and KF701 of group II, and they were accompanied by the sal genes, approximately 6-kb downstream of the $b p h$ genes. The KF715 strain of group II carried bph and sal gene clusters in the chromosome and also on a plasmid (pKF715A, $483 \mathrm{~kb}$ ) [16]. ICEs are thought to reintegrate into the recipient's chromosome immediately after transfer. However, a recent study suggested that certain ICEs, such as ICEBs1 from Bacillus subtilis [47] and SXT/R391 ICEs from Vibrio cholerae [48], are capable of autonomous replication. Transconjugants of P. putida AC30Bph+ and P. putida KT2440Bph+ carry the $b p h$-sal cluster as an extrachromosomal circular form [16]. The mobile element carrying the $b p h$-sal cluster replicates autonomously like plasmid, maintained stably, and consists of genes sharing homologies to components of the DNA replication and stabilization machinery.

The first example of ICE-harboring genes for the degradation of xenobiotic compounds is the $\mathrm{clc}$ element (ICEclc, $105 \mathrm{~kb}$ ) from P. knackmussii B13. ICEclc encodes for the catabolic pathway involved in 3- and 4-chlorocatechol degradation [43,49-51]. Besides this catabolic gene cluster, ICEclc has the core genes, such as type IV secretion system-encoding genes, relaxase, and integrase. ICEclc can excise through recombination between short direct repeats at either end (att $L$ and attR). The excised ICEclc can transfer to a new recipient cell through the conjugation apparatus and it integrates into the recipient's chromosome between the 18-bp sequence at the $3^{\prime}$ end of the tRNA-Gly gene on the chromosome $(a t t B)$ and the identical sequence on the excised ICEclc (attP), thereby restoring the tRNA-Gly gene. Both excision and integration are mediated by the IntB13 integrase. The ICE $\mathrm{E}_{b p h-s a l} \mathrm{~s}$ of group I (strains KF702, KF703, KF707, KF710, and KF716) were related to ICEclc in terms of the conjugation apparatus and the core gene set. However, the genetic organizations of $\mathrm{ICE}_{b p h-s a l} \mathrm{~S}$ are different from those of ICEclc. The integrases in the group I ICE $\mathrm{bph}_{\text {-sal }}$ were almost identical $(\sim 99 \%$ in amino acid sequences), but it was as low as $59 \%$ between that of $\mathrm{ICE}_{b p h-s a l}$ and ICEclc. Such low identity of the integrases between ICE $\mathrm{Ibph}_{\text {-sal }}$ and ICEclc reflected the differences of the insertion sites. The ICE $E_{b p h-s a l}$ s of group I were inserted at the $3^{\prime}$ - end of the tRNA-Gly gene (76 bp in length), which carries the CCC anticodon. ICEclc inserts into a number of tRNA-Gly genes, but only the genes which carry the GCC anticodon [51]. It should also be noted that the $\mathrm{ICE}_{\text {bph-sal }}$ in strains belonging to groups I and II are present in Pseudomonas spp., whereas other strains than Pseudomonas possess different $\mathrm{ICE}_{b p h}$ as seen in group IV strains, indicating that $\mathrm{ICE}_{b p h \text {-sal }}$ have restricted host ranges.

In this study, we found that various types of bph genes are present in ten different strains isolated from the same soil sample. Several lines of evidence suggested that many bph genes in these strains were present on the chromosome as an integrated form. However, it is also true that certain $\mathrm{ICE}_{b p h-s a l}$ is present stably as a plasmid. $\mathrm{ICE}_{b p h-s a l} \mathrm{KF} 715$ was stably maintained as a circular form in the two transconjugants, P. putida AC30Bph+ and P. putida KT2440Bph+. On the other hand, $\mathrm{ICE}_{\text {bph-sal }} \mathrm{KF} 715$ (circular) from P. putida AC30Bph+ and P. putida KT2440Bph+ seemed to integrate differently in another recipient P. putida F39/D. When P. putida AC30Bph+ was used as a donor strain, the largest SpeI DNA fragment of the F39/DBph+ transconjugant was hybridized with the KF715 bphA1 probe (Figure 9). When P. putida KT2440Bph+ was used as a donor strain, two copies of the bphA1 DNA were detected in the F39/DBph+ transconjugant strain at different positions (Figure 9). Investigations are currently underway to reveal how the $\mathrm{ICE}_{b p h-s a l} \mathrm{KF} 715$ is integrated in the genome of the F39/DBph+ transconjugants. The ICEclc of the P. knackmussii strain B13 was transferred by 
conjugation and integrated into two nonadjacent sites on the chromosome of toluene utilizing P. putida F1 [49]. Our repeated attempts to conjugally transfer the $\mathrm{ICE}_{b p h-s a l}$ of other strains than KF715 have not been successful. This may be due to a lack of expression of the integrase genes or mutations in certain gene(s) involved in the excision or conjugal transfer.

$\mathrm{ICE}_{b p h} \mathrm{KF} 708$ and $\mathrm{ICE}_{b p h} \mathrm{KF} 712$ were found in Cupriavidus and Comamonas, respectively. $\mathrm{ICE}_{b p h} \mathrm{KF} 708$ was almost identical to the ICE $\mathrm{KKS102}_{4677}$ from Acidovorax sp. KKS102, and they had several nucleotide differences, indicating that this type of $\mathrm{ICE}_{b p h}$ could be transferred between Cupriavidus and Acidovorax. The right wing corresponding to the core legion (33 kb) of ICE $\mathrm{E}_{\text {bph }} \mathrm{KF} 12$ and Tn4371 is highly conserved, but the left wing is diversified (Figure 8). This indicated that these two $\mathrm{ICE}_{b p h}$ were rearranged in the left wing. ICE $\mathrm{E}_{b p h \text {-sal }}$ (from the groups I and II strain) and ICE $\mathrm{E}_{b p h}$ (from the group IV strain) are typical ICEs, which possess type IV secretion machinery. However, there are few relationships between $\mathrm{ICE}_{b p h-s a l}$ and $\mathrm{ICE}_{b p h}$ in terms of gene organization, nucleotide sequence, and size (Figure 6, Figure 8). No significant identity was detected between the integrases of ICE $E_{b p h}$ and $\mathrm{ICE}_{b p h \text {-sal }}$. The region encoding two conjugative transfer components, the tra/trb genes adjacent to the $b p h$ gene cluster, was found in $\mathrm{ICE}_{b p h}$. The corresponding gene clusters were not found in ICE $\mathrm{E}_{b p h-s a l}$. Gene components downstream of the sal gene cluster are likely to be involved in conjugative transfer in $\mathrm{ICE}_{\text {bph-sal }}$; however, they have not been identified because of the lack of reliable homologous genes that are identified as conjugative transfer components in public databases. Although ICE $E_{b p h-s a l}$ and ICE $\mathrm{E}_{b p h}$ possess common genetic components involved in biphenyl catabolism, their platforms are different.

The biphenyl degrading bacteria are considered to be responsible for lignin degradation at the final stage. Lignin is a complex compound based on the phenylpropane structure and contains a variety of biphenyl related molecules. Thus, the $b p h$ genes could be very ancient and distributed across a wide range of soil bacteria. Mobilization of the bph genes in soil bacteria can be achieved through various mobile genetic elements, including ICEs, transposons, and plasmids. It is highly conceivable that these genes can be modified and rearranged in different ways in new host cells. The results in this study provide a better understanding as to how soil bacteria exchange genetic islands involved in the catabolism of aromatic compounds, as well as how such genes are rearranged and modified in the natural environment.

Supplementary Materials: The following tables and figure are available online at http://www.mdpi.com/20734425/10/5/404/s1. Table S1: Distribution of the catabolic genes for aromatic compounds and the heavy metal resistance genes in the biphenyl/PCB degrading KF strains. Tables S2-S13: Identity (\%) of nucleotide sequence of

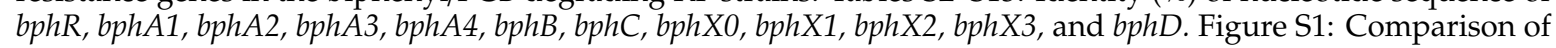
the $\operatorname{bphX3}(\mathrm{a})$ and $b p h D(\mathrm{~b})$ genes belonging to types I and II.

Author Contributions: K.F. planned the genome sequencing project and performed Southern blot hybridization analysis of the transconjugants. H.F. performed the sequence analysis of KF701 and KF702. H.S. performed the sequence analysis of KF703, KF708, and KF715. N.K. performed the sequence analysis of KF707. T.W. performed the sequence analysis of KF709 and KF710. J.H. participated in the sequence analysis of KF712 and KF716 and annotation of $\mathrm{ICE}_{b p h \text {-sal }} / \mathrm{ICE}_{b p h}$. A.S., T.F., and M.G. were involved in the whole genome annotation of the KF strains and completed the manuscript. All authors read and approved the final manuscript.

Funding: This work was partly supported by a research grant from the Institute for Fermentation, Osaka (G-2018-3-020 to T.W.). The APC was funded by a research grant from Beppu University (to H.F.).

Acknowledgments: We thank Atsushi Yamazoe and Akito Nishi for their useful discussion and suggestions.

Conflicts of Interest: The authors declare no conflict of interest.

\section{References}

1. Furukawa, K. Microbial degradation of polychlorinated biphenyls. In Biodegradation and Detoxification of Environmental Pollutants; Chakrabarty, A.M., Ed.; CRC Press: Boca Raton, FL, USA, 1982; pp. 33-57.

2. Abramowicz, D.A. Aerobic and anaerobic biodegradation of PCBs: A review. Crit. Rev. Biotechnol. 1990, 10, 241-251. [CrossRef]

3. Furukawa, K.; Fujihara, H. Microbial degradation of polychlorinated biphenyls: Biochemical and molecular features. J. Biosci. Bioeng. 2008, 105, 433-449. [CrossRef] [PubMed] 
4. Furukawa, K.; Tonomura, K.; Kamibayashi, A. Effect of chlorine substitution on the biodegradability of polychlorinated biphenyls. Appl. Env. Microbiol. 1978, 35, 223-227.

5. Furukawa, K.; Miyazaki, T. Cloning of a gene cluster encoding biphenyl and chlorobiphenyl degradation in Pseudomonas pseudoalcaligenes. J. Bacteriol. 1986, 166, 392-398. [CrossRef]

6. Toussaint, A.; Merlin, C.; Monchy, S.; Benotmane, M.A.; Leplae, R.; Mergeay, M.; Springael, D. The biphenyland 4-chlorobiphenyl-catabolic transposon Tn4371, a member of a new family of genomic islands related to IncP and Ti plasmids. Appl. Env. Microbiol. 2003, 69, 4837-4845. [CrossRef] [PubMed]

7. Ohtsubo, Y.; Ishibashi, Y.; Naganawa, H.; Hirokawa, S.; Atobe, S.; Nagata, Y.; Tsuda, M. Conjugal transfer of polychlorinated biphenyl/biphenyl degradation genes in Acidovorax sp. strain KKS102, which are located on an integrative and conjugative element. J. Bacteriol. 2012, 194, 4237-4248. [CrossRef]

8. Masai, E.; Sugiyama, K.; Iwashita, N.; Shimizu, S.; Hauschild, J.E.; Hatta, T.; Kimbara, K.; Yano, K.; Fukuda, M. The $b p h D E F$ meta-cleavage pathway genes involved in biphenyl/polychlorinated biphenyl degradation are located on a linear plasmid and separated from the initial bphACB genes in Rhodococcus sp. strain RHA1. Gene 1997, 187, 141-149. [CrossRef]

9. Shimizu, S.; Kobayashi, H.; Masai, E.; Fukuda, M. Characterization of the 450-kb linear plasmid in a polychlorinated biphenyl degrader, Rhodococcus sp. strain RHA1. Appl. Env. Microbiol. 2001, 67, 2021-2028. [CrossRef] [PubMed]

10. Watanabe, T.; Inoue, R.; Kimura, N.; Furukawa, K. Versatile transcription of biphenyl catabolic bph operon in Pseudomonas pseudoalcaligenes KF707. J. Biol. Chem. 2000, 275, 31016-31023. [CrossRef]

11. Fujihara, H.; Yoshida, H.; Matsunaga, T.; Goto, M.; Furukawa, K. Cross-regulation of biphenyl- and salicylate-catabolic genes by two regulatory systems in Pseudomonas pseudoalcaligenes KF707. J. Bacteriol. 2006, 188, 4690-4697. [CrossRef]

12. Kumamaru, T.; Suenaga, H.; Mitsuoka, M.; Watanabe, T.; Furukawa, K. Enhanced degradation of polychlorinated biphenyls by directed evolution of biphenyl dioxygenase. Nat. Biotechnol. 1998, 16, 663. [CrossRef] [PubMed]

13. Suenaga, H.; Goto, M.; Furukawa, K. Emergence of multifunctional oxygenase activities by random priming recombination. J. Biol. Chem. 2001, 276, 22500-22506. [CrossRef] [PubMed]

14. Suenaga, H.; Mitsuoka, M.; Ura, Y.; Watanabe, T.; Furukawa, K. Directed evolution of biphenyl dioxygenase: Emergence of enhanced degradation capacity for benzene, toluene, and alkylbenzenes. J. Bacteriol. 2001, 183, 5441-5444. [CrossRef]

15. Furukawa, K.; Hayase, N.; Taira, K.; Tomizuka, N. Molecular relationship of chromosomal genes encoding biphenyl/polychlorinated biphenyl catabolism: Some soil bacteria possess a highly conserved bph operon. J. Bacteriol. 1989, 171, 5467-5472. [CrossRef]

16. Suenaga, H.; Fujihara, H.; Kimura, N.; Hirose, J.; Watanabe, T.; Futagami, T.; Goto, M.; Shimodaira, J.; Furukawa, K. Insights into the genomic plasticity of Pseudomonas putida KF715, a strain with unique biphenyl-utilizing activity and genome instability properties. Environ. Microbiol. Rep. 2017, 9, 589-598. [CrossRef]

17. Fujihara, H.; Yamazoe, A.; Hosoyama, A.; Suenaga, H.; Kimura, N.; Hirose, J.; Watanabe, T.; Futagami, T.; Goto, M.; Furukawa, K. Draft genome sequence of Pseudomonas abietaniphila KF701 (NBRC110664), a polychlorinated biphenyl-degrading bacterium isolated from biphenyl-contaminated soil. Genome Announc. 2015, 3, e00473-15. [CrossRef] [PubMed]

18. Suenaga, H.; Yamazoe, A.; Hosoyama, A.; Kimura, N.; Hirose, J.; Watanabe, T.; Fujihara, H.; Futagami, T.; Goto, M.; Furukawa, K. Draft genome sequence of the polychlorinated biphenyl-degrading bacterium Pseudomonas putida KF703 (NBRC 110666) isolated from biphenyl-contaminated soil. Genome Announc. 2015, 3, e00142-15. [CrossRef]

19. Kimura, N.; Watanabe, T.; Suenaga, H.; Fujihara, H.; Futagami, T.; Goto, M.; Hanada, S.; Hirose, J. Pseudomonas furukawaii sp. nov., a polychlorinated biphenyl-degrading bacterium isolated from biphenyl-contaminated soil in Japan. Int. J. Syst. Evol. Microbiol. 2018, 68, 1429-1435. [CrossRef]

20. Suenaga, H.; Yamazoe, A.; Hosoyama, A.; Kimura, N.; Hirose, J.; Watanabe, T.; Fujihara, H.; Futagami, T.; Goto, M.; Furukawa, K. Draft genome sequence of the polychlorinated biphenyl-degrading bacterium Cupriavidus basilensis KF708 (NBRC 110671) isolated from biphenyl-contaminated soil. Genome Announc. 2015, 3, e00143-15. [CrossRef] 
21. Hirose, J.; Yamazoe, A.; Hosoyama, A.; Kimura, N.; Suenaga, H.; Watanabe, T.; Fujihara, H.; Futagami, T.; Goto, M.; Furukawa, K. Draft genome sequence of the polychlorinated biphenyl-degrading bacterium Comamonas testosteroni KF712 (NBRC 110673). Genome Announc. 2015, 3, e01214-15. [CrossRef]

22. Nishi, A.; Tominaga, K.; Furukawa, K. A 90-kilobase conjugative chromosomal element coding for biphenyl and salicylate catabolism in Pseudomonas putida KF715. J. Bacteriol. 2000, 182, 1949-1955. [CrossRef]

23. Zylstra, G.J.; Gibson, D.T. Toluene degradation by Pseudomonas putida F1. Nucleotide sequence of the todC1C2BADE genes and their expression in Escherichia coli. J. Biol. Chem. 1989, 264, 14940-14946.

24. Fujihara, H.; Yamazoe, A.; Hosoyama, A.; Suenaga, H.; Kimura, N.; Hirose, J.; Watanabe, T.; Futagami, T.; Goto, M.; Furukawa, K. Draft genome sequence of Pseudomonas aeruginosa KF702 (NBRC 110665), a polychlorinated biphenyl-degrading bacterium isolated from biphenyl-contaminated soil. Genome Announc. 2015, 3, e00517-15. [CrossRef]

25. Triscari-Barberi, T.; Simone, D.; Calabrese, F.M.; Attimonelli, M.; Hahn, K.R.; Amoako, K.K.; Turner, R.J.; Fedi, S.; Zannoni, D. Genome sequence of the polychlorinated-biphenyl degrader Pseudomonas pseudoalcaligenes KF707. J. Bacteriol. 2012, 194, 4426-4427. [CrossRef]

26. Watanabe, T.; Yamazoe, A.; Hosoyama, A.; Fujihara, H.; Suenaga, H.; Hirose, J.; Futagami, T.; Goto, M.; Kimura, N.; Furukawa, K. Draft genome sequence of Cupriavidus pauculus strain KF709, a biphenyl-utilizing bacterium isolated from biphenyl-contaminated soil. Genome Announc. 2015, 3, e00222-15. [CrossRef]

27. Watanabe, T.; Yamazoe, A.; Hosoyama, A.; Fujihara, H.; Suenaga, H.; Hirose, J.; Futagami, T.; Goto, M.; Kimura, N.; Furukawa, K. Draft genome sequence of Pseudomonas toyotomiensis KF710, a polychlorinated biphenyl-degrading bacterium isolated from biphenyl-contaminated soil. Genome Announc. 2015, 3, e0223-15. [CrossRef]

28. Suenaga, H.; Yamazoe, A.; Hosoyama, A.; Kimura, N.; Hirose, J.; Watanabe, T.; Fujihara, H.; Futagami, T.; Goto, M.; Furukawa, K. Complete genome sequence of the polychlorinated biphenyl-degrading bacterium Pseudomonas putida KF715 (NBRC 110667) isolated from biphenyl-contaminated soil. Genome Announc. 2017, 5, e01624-16. [CrossRef]

29. Hirose, J.; Yamazoe, A.; Hosoyama, A.; Kimura, N.; Suenaga, H.; Watanabe, T.; Fujihara, H.; Futagami, T.; Goto, M.; Furukawa, K. Draft genome sequence of the polychlorinated biphenyl-degrading bacterium Pseudomonas stutzeri KF716 (NBRC 110668). Genome Announc. 2015, 3, e01215-15. [CrossRef]

30. Aziz, R.K.; Bartels, D.; Best, A.A.; DeJongh, M.; Disz, T.; Edwards, R.A.; Formsma, K.; Gerdes, S.; Glass, E.M.; Kubal, M.; et al. The RAST server: Rapid annotations using subsystems technology. BMC Genom. 2008, 9, 75. [CrossRef]

31. Sullivan, M.J.; Petty, N.K.; Beatson, S.A. Easyfig: A genome comparison visualizer. Bioinformatics 2011, 27, 1009-1010. [CrossRef]

32. Li, K.-B. ClustalW-MPI: ClustalW analysis using distributed and parallel computing. Bioinformatics 2003, 19, 1585-1586. [CrossRef]

33. Tamura, K.; Stecher, G.; Peterson, D.; Filipski, A.; Kumar, S. MEGA6: molecular evolutionary genetics analysis version 6.0. Mol. Biol. Evol. 2013, 30, 2725-2729. [CrossRef]

34. Sambrook, J.; Russell, D.W. Molecular Cloning: A Laboratory Manual, 3rd ed.; CSHL Press: Cold Spring Harbor, NY, USA, 2001.

35. Erickson, B.D.; Mondello, F.J. Nucleotide sequencing and transcriptional mapping of the genes encoding biphenyl dioxygenase, a multicomponent polychlorinated-biphenyl-degrading enzyme in Pseudomonas strain LB400. J. Bacteriol. 1992, 174, 2903-2912. [CrossRef] [PubMed]

36. Shingler, V.; Powlowski, J.; Marklund, U. Nucleotide sequence and functional analysis of the complete phenol/3,4-dimethylphenol catabolic pathway of Pseudomonas sp. strain CF600. J. Bacteriol. 1992, 174, 711-724. [CrossRef]

37. Brown, N.L.; Misra, T.K.; Winnie, J.N.; Schmidt, A.; Seiff, M.; Silver, S. The nucleotide sequence of the mercuric resistance operons of plasmid R100 and transposon Tn501: further evidence for mer genes which enhance the activity of the mercuric ion detoxification system. Mol. Gen. Genet. 1986, 202, 143-151. [CrossRef]

38. Intorne, A.C.; de Oliveira, M.V.V.; de M Pereira, L.; de Souza Filho, G.A. Essential role of the $c z c$ determinant for cadmium, cobalt and zinc resistance in Gluconacetobacter diazotrophicus PAl 5. Int. Microbiol. Off. J. Span. Soc. Microbiol. 2012, 15, 69-78. 
39. Ohtsubo, Y.; Delawary, M.; Kimbara, K.; Takagi, M.; Ohta, A.; Nagata, Y. BphS, a key transcriptional regulator of $b p h$ genes involved in polychlorinated biphenyl/biphenyl degradation in Pseudomonas sp. KKS102. J. Biol. Chem. 2001, 276, 36146-36154. [CrossRef]

40. Christie, P.J.; Whitaker, N.; González-Rivera, C. Mechanism and structure of the bacterial type IV secretion systems. Biochim. Biophys. Acta 2014, 1843, 1578-1591. [CrossRef] [PubMed]

41. Mavrodi, D.V.; Loper, J.E.; Paulsen, I.T.; Thomashow, L.S. Mobile genetic elements in the genome of the beneficial rhizobacterium Pseudomonas fluorescens Pf-5. BMC Microbiol. 2009, 9, 8. [CrossRef]

42. Johnson, C.M.; Grossman, A.D. Integrative and conjugative elements (ICEs): What they do and how they work. Annu. Rev. Genet. 2015, 49, 577-601. [CrossRef]

43. Gaillard, M.; Vallaeys, T.; Vorhölter, F.J.; Minoia, M.; Werlen, C.; Sentchilo, V.; Pühler, A.; van der Meer, J.R. The clc element of Pseudomonas sp. strain B13, a genomic island with various catabolic properties. J. Bacteriol. 2006, 188, 1999-2013. [CrossRef]

44. Bellanger, X.; Payot, S.; Leblond-Bourget, N.; Guédon, G. Conjugative and mobilizable genomic islands in bacteria: Evolution and diversity. FEMS Microbiol. Rev. 2014, 38, 720-760. [CrossRef]

45. Juhas, M.; van der Meer, J.R.; Gaillard, M.; Harding, R.M.; Hood, D.W.; Crook, D.W. Genomic islands: Tools of bacterial horizontal gene transfer and evolution. FEMS Microbiol. Rev. 2009, 33, 376-393. [CrossRef]

46. Wozniak, R.A.F.; Waldor, M.K. Integrative and conjugative elements: Mosaic mobile genetic elements enabling dynamic lateral gene flow. Nat. Rev. Microbiol. 2010, 8, 552-563. [CrossRef]

47. Lee, C.A.; Babic, A.; Grossman, A.D. Autonomous plasmid-like replication of a conjugative transposon. Mol. Microbiol. 2010, 75, 268-279. [CrossRef]

48. Carraro, N.; Poulin, D.; Burrus, V. Replication and active partition of integrative and conjugative elements (ICEs) of the SXT/R391 family: The line between ICEs and conjugative plasmids is getting thinner. PLoS Genet. 2015, 11, e1005298. [CrossRef]

49. Ravatn, R.; Studer, S.; Springael, D.; Zehnder, A.J.B.; van der Meer, J.R. Chromosomal integration, tandem amplification, and deamplification in Pseudomonas putida F1 of a 105-kilobase genetic element containing the chlorocatechol degradative genes from Pseudomonas sp. strain B13. J. Bacteriol. 1998, 180, 4360-4369.

50. Sentchilo, V.; Ravatn, R.; Werlen, C.; Zehnder, A.J.B.; van der Meer, J.R. Unusual integrase gene expression on the clc genomic island in Pseudomonas sp. strain B13. J. Bacteriol. 2003, 185, 4530-4538. [CrossRef]

51. Sentchilo, V.; Czechowska, K.; Pradervand, N.; Minoia, M.; Miyazaki, R.; van der Meer, J.R. Intracellular excision and reintegration dynamics of the ICEclc genomic island of Pseudomonas knackmussii sp. strain B13. Mol. Microbiol. 2009, 72, 1293-1306. [CrossRef] 